\title{
François Rossignon, un naturalista francés cautivo de las aves de Caupolican (Beni y La Paz, 1833-1847)
}

François Rossignon, un naturaliste français captivé par les oiseaux de Caupolican (Beni et La Paz, 1833-1874)

François Rossignon, a french naturalist who was fascinated by the birds of Caupolican (Beni and La Paz, 1833-1847)

\section{Carmen Beatriz Loza}

\section{OpenEdition}

\section{Journals}

Edición electrónica

URL: http://journals.openedition.org/bifea/5597

DOI: 10.4000/bifea.5597

ISSN: 2076-5827

\section{Editor}

Institut Français d'Études Andines

\section{Edición impresa}

Fecha de publicación: 1 mayo 2005

Paginación: 59-80

ISSN: 0303-7495

\section{Referencia electrónica}

Carmen Beatriz Loza, «François Rossignon, un naturalista francés cautivo de las aves de Caupolican (Beni y La Paz, 1833-1847) », Bulletin de l'Institut français d'études andines [En línea], 34 (1) | 2005, Publicado el 08 abril 2005, consultado el 02 diciembre 2020. URL : http://journals.openedition.org/ bifea/5597 ; DOI : https://doi.org/10.4000/bifea.5597

\section{(c) $(1) \odot$}

Les contenus du Bulletin de l'Institut français d'études andines sont mis à disposition selon les termes de la licence Creative Commons Attribution - Pas d'Utilisation Commerciale - Pas de Modification 4.0 International. 


\title{
François Rossignon, un naturalista francés cautivo de las aves de Caupolican (Beni y La Paz, 1833-1847)
}

\author{
Carmen Beatriz Loza*
}

\section{Resumen}

El acompañamiento que recibió Alcide Dessalines d'Orbigny (1826-1878) durante su viaje por la América meridional es un tema evocado por la historiografía, pero raramente estudiado. Este artículo busca probar, en sus líneas generales, que el papel de los ayudantes científicos se desvanece en la narrativa de los viajeros, a pesar de la importante contribución a su empresa. El silenciamiento de los colaboradores contribuyó a perpetuar la imagen tradicional de naturalistas obrando solos. En realidad, la expedición del Muséum national d'Histoire naturelle de París dirigida por d'Orbigny en Bolivia recibió el aporte de dos compatriotas suyos entre otros muchos de diversas nacionalidades. Uno de sus compañeros, fue François Rossignon (?-1846).

La propuesta acá es presentar, por primera vez, al francés Rossignon como naturalista, taxidermista y ocasionalmente funcionario del estado boliviano, siguiendo las trazas de sus vivencias en la provincia Caupolican. Rossignon, durante más de dieciséis años, logró formar una maravillosa colección de ornitología neo-tropical, la cual generó recelo, interés y hasta su propia muerte. Este artículo conjetura acerca de las causas de su deceso y el paradero de su colección. De esa manera, saca a luz el funcionamiento de las redes locales que constituían y comercializaban colecciones de objetos de historia natural a mediados del siglo XIX desde el Beni y Santa Cruz de la Sierra.

Sugiere que Rossignon fue en gran parte el preparador de la colección de ornitología neo-tropical que llegó al Muséum national d'Histoire naturelle de París entre 1830 y 1834; asimismo, un importante informante para la elaboración del Viaje a la América Meridional. Posiblemente d'Orbigny retomó el relato de vivencia en Caupolican de Rossignon para escribir sobre esa provincia que desconocía,

* Sociedad Geográfica de La Paz. Correo electrónico: lozaquipu@yahoo.es, casilla de correo 2907, La Paz-Bolivia. Este trabajo es un fragmento de una investigación más amplia que venimos realizando en torno a la red de Alcide Dessalines d'Orbigny. Agradezco profundamente a Jean-Pierre Chaumeil, Pascal Riviale y Jean-Joinville Vacher por su lectura crítica y sugestiva, pero sobre todo por su apoyo. Asimismo, recibí la colaboración del Área Natural de Manejo Integrado Nacional «Apolobamba» en Bolivia; la Biblioteca y Archivo del Congreso Nacional de Bolivia; Biblioteca y Archivo Nacionales de Bolivia y Biblioteca del Max-Planck-Institut für Wissenchaftsgeschichte. 
pero la presentó en la Descripción geográfica, histórica y estadística de Bolivia (d'Orbigny, 1845). La información recogida en los archivos bolivianos cambia radicalmente la actual perspectiva, según la cual d'Orbigny basó todas sus narraciones en sus propias experiencias de viaje.

Palabras claves - Alcide Dessalines d'Orbigny, taxidermia, naturalista-viajero, Museo nacional de historia natural de París, Museo nacional de historia natural de La Paz, Beni, Caupolican, Santa Cruz de la Sierra.

\title{
François Rossignon, un naturaliste français captivé par les oiseaux de Caupolican (Beni et La Paz, 1833-1874)
}

\section{Résumé}

L'aide qu'Alcide Dessalines d'Orbigny (1826-1878) a reçu le long de son voyage en Amérique méridionale est un sujet évoqué par l'historiographie mais qui a cependant rarement été étudié. Cet article cherche à montrer, dans ses lignes générales, que le rôle des assistants scientifiques se dilue dans les récits des voyageurs, malgré leur importante contribution. Le silence des collaborateurs a contribué à perpétuer l'image traditionnelle des naturalistes travaillant seuls. En réalité, l'expédition du Muséum national d'Histoire naturelle de Paris dirigée par d'Orbigny en Bolivie reçut l'apport de deux de ses compatriotes parmi beaucoup d'autres de diverses nationalités. Un de ses compagnons fut François Rossignon ( ?-1846).

Ce texte propose de présenter, pour la première fois, le français Rossignon comme naturaliste, taxidermiste et parfois fonctionnaire de l'État bolivien en suivant les traces de son expérience dans la province de Caupolican. Pendant plus de seize ans, Rossignon réussit à constituer une merveilleuse collection d'ornithologie néo-tropicale, laquelle provoqua de la méfiance, de l'intérêt et même sa propre mort. Cet article laisse entrevoir les causes de son décès et le destin de sa collection. De cette manière, il met en lumière le fonctionnement des réseaux locaux qui constituaient et commercialisaient des collections d'objets d'histoire naturelle à la moitié du XIXe siècle au Beni et à Santa Cruz de la Sierra.

Cet article suggère que Rossignon fut en grande partie le préparateur de la collection d'ornithologie néo-tropicale qui est arrivée au Muséum national d'Histoire naturelle de Paris entre 1830 et 1834. De même, il fut un informateur important pour l'élaboration du Voyage en Amérique Méridionale. D'Orbigny a probablement reprit le récit du séjour à Caupolican de Rossignon afin d'écrire sur cette province qu'il ne connaissait pas, mais qu'il présenta dans la Description géographique, historique et statistique de la Bolivie (d'Orbigny, 1845). L'information recueillie aux archives boliviennes change radicalement la perspective actuelle, selon laquelle d'Orbigny a basé tous ses récits sur ses propres expériences de voyage.

Mots-clés - Alcide Dessalines d'Orbigny, taxidermie, naturaliste-voyageur, Muséum national d'histoire naturelle de Paris, Muséum national d'Histoire naturelle de La Paz, Beni, Caupolican, Santa Cruz de la Sierra.

\section{François Rossignon, a french naturalist who was fascinated by the birds of Caupolican (Beni and La Paz, 1833-1847)}

\begin{abstract}
The accompaniment provided to Alcide Dessalines d'Orbigny (1826-1878) during his travel through Southern America is a theme alluded to in historical writings, but seldom studied. This paper intends to prove, in broad outline, that the role of scientific assistants fades away in the traveler's narrative, in spite of its important contribution. The silence of his collaborators contributed to perpetuate the traditional image of naturalists working by themselves. In fact, the Parisian Muséum national d'histoire naturelle expedition led by d'Orbigny in Bolivia, received contributions from two of his compatriots
\end{abstract}


as well as others belonging to several nationalities. One of his companions in his traveler was François Rossignon (?-1846).

The purpose of this article is to introduce, for the very first time the Frenchman Rossignon as a naturalist, taxidermist, and occasionally as a Bolivian government official, following the traces of his experiences in the province of Caupolican. Rossignon, during more than sixteen years, was able to create a marvelous neo-tropical ornithological collection, which caused suspicion, interest, and even his own death. This article speculates about the causes of his demise and the his location of his collection. In this way, the article shed light on the functioning of local networks that constituted and commercialized natural history collections in the mid-19th century from Beni and Santa Cruz de la Sierra.

It is suggested that Rossignon was in large part the preparatory of the neo-tropical ornithological collection that arrived to the Muséum national d'histoire naturelle of Paris between 1830 and 1834. In addition, he was an important informant for the elaboration of Viaje a la América Meridional. It is possible that d'Orbigny used Rossignon's experience of living in Caupolican to write about that province that he did not know personally, but is presented in Descripción geográfica, histórica y estadística de Bolivia (d'Orbigny, 1845). Information gathered in Bolivian archives radically changes the current perspective on the information upon which d'Orbigny based all his narratives concerning his own travel experiences.

Key words - Alcide Dessalines d'Orbigny, taxidermy, naturalist-traveler, National Museum of Natural History of Paris, National Museum of Natural History of La Paz, Beni, Caupolican, Santa Cruz de la Sierra.

«Estamos dispuestos si es necesario a entregarle a este viaje, toda nuestra existencia»

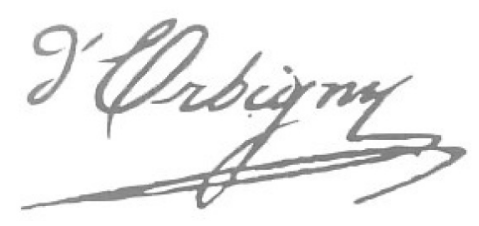

El bicentenario del nacimiento del célebre viajero y naturalista francés Alcide Dessalines d'Orbigny (1826-1878) ha generado una vasta producción bibliográfica en la que resaltan nuevas investigaciones, reproducciones de artículos dispersos y raros con interesante información acerca de sus viajes realizados desde 1826 hasta 1833, cuando d'Orbigny recorre la América meridional como viajero-naturalista del Muséum national d'Histoire naturelle de París, justamente cuando las nacientes repúblicas independientes americanas se interesaban en las fuentes naturales como un recurso potencial para su desarrollo y proyección futuras. Simultáneamente, el bicentenario fue ocasión para la aparición de nuevas investigaciones y trabajos de compilación (d'Orbigny, 2002b), sin olvidar las reediciones críticas de algunas de las obras científicas de d'Orbigny realizadas en América (d'Orbigny, 2002a, I-IV) y Europa, sin que por ello se agote la inmensa producción científica que dejó como legado'. 


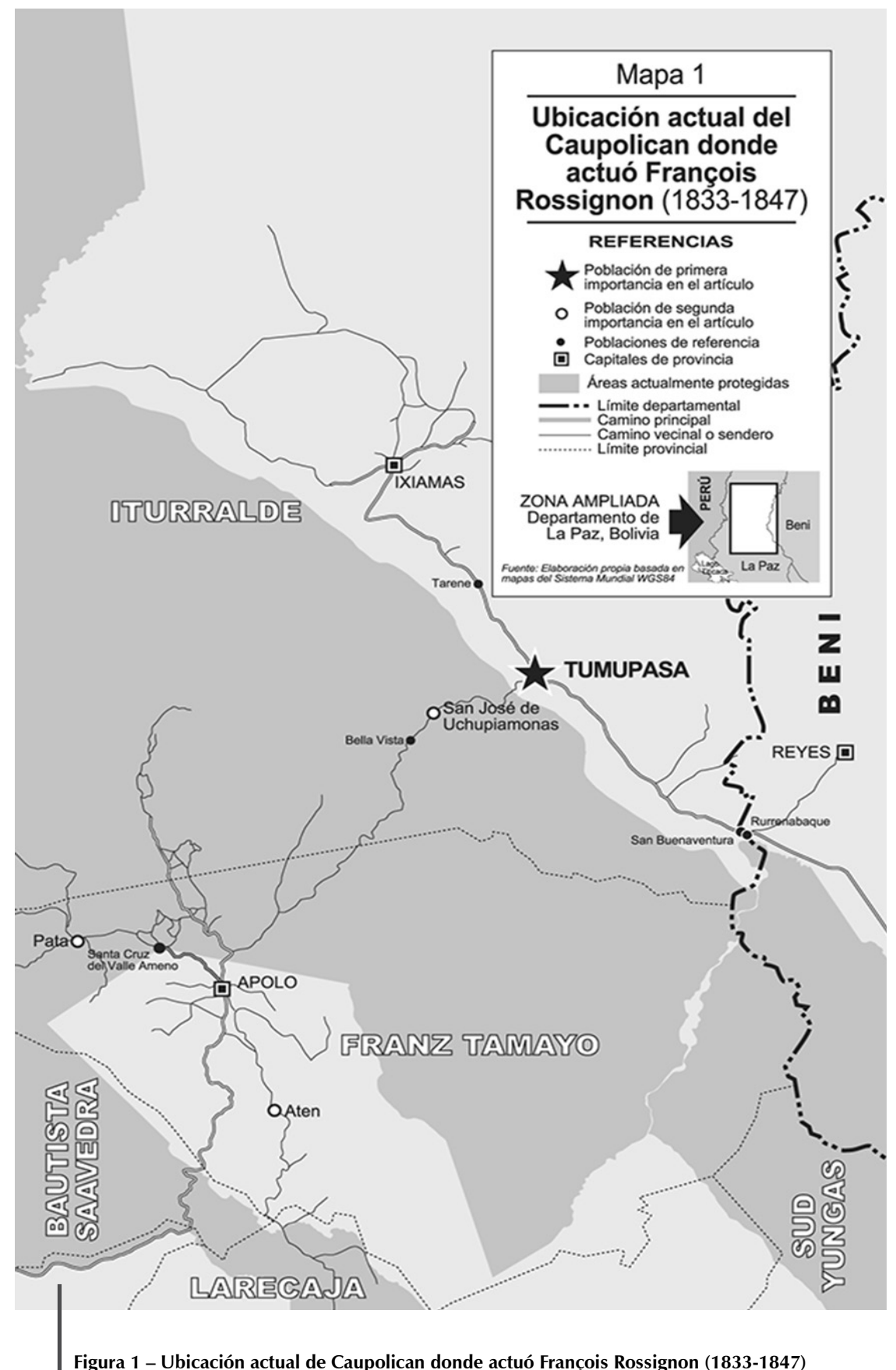

Fuente - Elaboración propia basada en mapas del Sistema Nacional WGS84 
La producción generada a partir de esa celebración muestra un contraste entre las temáticas abordadas y las formas narrativas adoptadas para dar cuenta del trabajo y desafíos del viajero-naturalista. En Bolivia se enfatiza en la contextualización intelectual de su pensamiento, en el marco del proceso político ideológico de la formación de la Nueva República (Albarracín Milán, 1976; 2002). Asimismo, en el impacto que tuvo en la visión de los bolivianos a través de una compilación de los textos más relevantes escritos desde el siglo XIX hasta el XXI (Arze Aguirre, 2002). Recopilación que pone al descubierto la ausencia de interés por aspectos puntuales, a excepción de algunos análisis (Moreno, 2002: 41-54; Cárdenas, 2002: 163-171; Díaz Arguedas, 2002: 195-209; Mendoza, 2002b: 235-258; Parejas Moreno \& Muñoz Reyes de Parejas, 2002: 267-294; Parejas Moreno, 2002: 295305). Posiblemente, este impacto se debía, como enfatiza Albarracín Millán, a la limitada recepción de la obra de d'Orbigny en Bolivia como consecuencia del reducido número de ejemplares de su obra llegado de Francia a Bolivia, la inaccesibilidad a la lengua francesa y la tardía traducción al castellano en el siglo XX.

Deja al descubierto, asimismo, la falta de una aproximación desde la historia de la ciencia que, desde mi punto de vista, es esencial para tener una idea más precisa de su empresa, pues las ciencias naturales, sus aplicaciones y la geografía han sido las principales y preferidas preocupaciones de d'Orbigny². Justamente estos vacíos comprobados son llenados parcialmente en Francia con motivo de la exposición que el Muséum national d'Histoire naturelle consagró a d'Orbigny (cf. Taquet, 2002).

Sin embargo, la investigación del naturalista-viajero debería ser leída a la luz del papel desempeñado por los auxiliares científicos cuya presencia es fantasmal en las narraciones de su periplo en la América meridional, en parte por la limitada atención prestada a la composición de la expedición que logró conformar a medida que se adentraba en la exploración interior de este territorio. Al respecto, el historiador, archivista y bibliógrafo potosino, Gunnar Mendoza Loza (1914-1994), puntualiza aspectos desconocidos sobre la conformación de su equipo en Bolivia. Justamente este texto se inicia donde se había instalado el suspenso y pretende responder a algunos de los problemas planteados por este autor (Mendoza, 2002a: 211-234).

Sabemos que durante la preparación de su viaje, d'Orbigny se ocupó de tramitar varias visas para ciudadanos franceses3. ¿Llegaron a realizar el viaje? ¿De quiénes se trataba? ¿Algún papel jugaron en la expedición, aunque d'Orbigny no los mencione explícitamente en sus obras? Durante mucho tiempo la historiografía boliviana aceptó la idea que «recorrió de parte a parte el territorio patrio, generalmente a pie, acompañado solamente de sus dos fieles guías yuracarés» (Muñoz Reyes, 2002: 259); dejando de lado la cantidad de referencias que inmiscuyen a muchos otros actores. Información que, complementada con la administrativa sugiere que «llegó con dos ayudantes franceses de los cuales se sabe muy poco» y menos aún de su destino en Bolivia4. La presencia de estos franceses debe ser verificada y no solo asumida.

2 D’Orbigny dice: «[...] pude seguir éstos mis estudios predilectos de una manera más especial, procurando iluminar mi inteligencia y beber la instrucción en esta fuente, verdadero emporio de las luces y del saber» (d'Orbigny, 1845: i). Cf. Archivo Nacional de Bolivia, Ministerio del Interior, 1880, T 34, № 14. «Al Señor Presidente de la Republica Boliviana de Alcide Dessalines d'Orbigny» (La Paz, 12 de junio de 1830). ANB/MI. Ministerio del Interior Tomo 28, No 12 «Al Señor Ministro de Relaciones exteriores en Chuquisaca de Alcide Dessalines d'Orbigny» (La Paz, 4 de julio de 1830), 2fs. ANB/Ml. Ministerio del Interior. «A su gracia el Ministro del Interior de Alcide Dessalines d'Orbigny» (Chuquisaca febrero de 1833) $1 \mathrm{f}$.

3 Datos transmitidos gentilmente por Jean-Joinville Vacher, Directeur de I'Institut de Recherche pour le Développement, La Paz. Agradezco su colaboración en proporcionarme numerosa bibliografía.

4 Comentarios de Javier Mendoza Pizarro al texto de su padre Gunnar Mendoza Loza (Mendoza L., 2001:224). 
Despejaremos estas dudas rastreando en sus recorridos vividos, en su tránsito por uno y otro espacio y en la inscripción de unas huellas en la documentación boliviana, como también en la francesa. Privilegiamos la fuente administrativa y judicial generada en la presidencia de Andrés de Santa Cruz y Calahumana (1829-1839) y José Ballivián (18411847). Estos gobernantes, a su vez, instruyeron a diferentes instancias administrativas a colaborar con la expedición, de tal manera que se ha generado una valiosa documentación oficial en diversas dependencias ministeriales y prefecturales del país. Asimismo, recurrimos a la compilación parcial de las Lettres d'Amérique d'Alcide d'Orbigny editadas por Gilles Béraud con la colaboración de Enric \& Daniel Dory (d'Orbigny, 2002b).

Apoyada en esa documentación, probaré que los franceses sirvieron de escolta, dibujantes, coleccionistas e informantes. En otras palabras, de agentes centrales de la legitimación de la autoridad científica europea. Además, le permitieron a d'Orbigny establecer múltiples redes de información para obtener muestras de la naturaleza, coleccionarlas y guardarlas para el Muséum. Tanto así que uno de sus acompañantes, François Rossignon, permaneció en el departamento del Beni hasta su deceso. Para comprender el desenlace de este acontecimiento intentaré reconstruir la investigación judicial acerca de su muerte que origina la hipótesis de un suicidio por parte de las autoridades bolivianas. Mi propósito es presentar los posibles móviles para que se produzca su muerte, basándome en los testimonios de importantes testigos bolivianos. Al abordar estos aspectos, no pretendo detenerme únicamente en una experiencia individual, más bien mostrar que esta excede y problematiza al sujeto, remitiéndonos a sus redes en el trabajo de investigación científica y el comercio de objetos naturales destinados a las instituciones francesas de producción de historia natural.

La narración de lo ocurrido se desarrolla básicamente en una zona de contacto entendida como un intento de invocar la presencia conjunta, espacial y temporal, de sujetos -anteriormente separados por divisiones geográficas e históricas - cuyas trayectorias se intersectan, entrando en interacción, en una trabazón de comprensión y prácticas, pero también en algunas ocasiones, dentro de relaciones de poder radicalmente asimétricas (Pratt, 1997 [1992]: 26). Geográficamente, la zona de contacto se sitúa en la provincia de Caupolican, al noroeste del departamento del Beni y de manera secundaria en otros puntos del departamento de Santa Cruz de la Sierra y la ciudad de La Paz.

La presencia de Rossignon en Caupolican nos permite preguntarnos: ¿cómo se explica que d'Orbigny produjo una narración y presentó nuevas unidades formales de organismos o taxones provenientes de un espacio donde nunca estuvo? Sostendremos que Rossignon aportó considerablemente al trabajo de investigación de d'Orbigny, sobre todo como taxidermista, encargado de preparar las colecciones de ornitología neo-tropical enviadas a los museos en París y el museo de historia natural creado en esa ocasión en La Paz. Asimismo, aportó como informante para la redacción de la Descripción geográfica, histórica y estadística de Bolivia centrada en Caupolican (d'Orbigny, 1845).

De esta manera volcaremos la mirada a las redes de informantes y ayudantes científicos que acallados o silenciosos coadyuvan a la expedición del Muséum y la producción científica francesa del siglo XIX. Ellos han quedado en el anonimato, a pesar de haber sido infatigables trabajadores midiendo, reconociendo, anotando, preservando, dibujando en las montañas, valles y selvas de América. Me parece que es hora de develar su actuación para desmitificar la idea de que las exploraciones fueron producto exclusivo de hombres cuya fuerza, competencia y talento eran descomunales, al extremo que fueron capaces de realizar la hazaña del viaje completamente solos. Por esa razón, en lo que sigue, pretendo llevar a primer plano las dimensiones interactivas de los ayudantes científicos, dimensiones estas tantas veces ignoradas o suprimidas por relatos destinados a la exaltación de un solo personaje. Fijaremos, entonces, durante un tiempo, el recorrido de Rossignon e intentaremos, con la ayuda de varias fuentes, mostrar su actuación y aporte. 


\section{DE LA PRESENCIA DE OTROS FRANCESES EN LA EXPEDICIÓN DE D'ORBIGNY}

\subsection{Una sucesión de referencias delatoras de silencio}

En general, llama la atención las escasas marcas discursivas que d'Orbigny deja pasar acerca de sus acompañantes y auxiliares científicos franceses. A pesar de ello, en sus escritos se han filtrado pequeñas frases delatando que no estuvo solo en América meridional. Las cartas preparatorias explicitan que durante la organización de su viaje, logró animar a un joven compatriota - Benjamín Trion - a aventurarse a América por cuenta propia, desempeñando las funciones de su ayudante (Béraud, 2000:1126-1127). Ignoramos el tiempo de permanencia al lado de d'Orbigny.

Las noticias acerca de la compañía de los franceses, un dibujante y un «preparador» otaxidermista, son breves, claves y novedosas, gracias a dos cartas 5 donde confirma su presencia:

«Maintenant je ne voyage plus comme un pauvre diable. J'ai avec moi un peintre, un préparateur et deux jeunes gens que le gouvernement de Bolivie me donne pour les instruire et pour aider, de sorte que mon expédition se compose toujours de cinq personnes sans compter les Indiens. Et maintenant ils sont trop heureux que je veuille bien manger à leur table». (d'Orbigny, 2002b: 75) (El énfasis nos pertenece.)

La presencia de por lo menos uno de los franceses reaparece en el viaje a Chiquitos en 1830, cuando deja al descubierto que:

«No solo las grandes ciudades encierran una gran diversidad de lenguas, la prueba más evidente era este campamento mío. Al escuchar los distintos sonidos que llegaban a mis oídos, quise darme cuenta del número de lenguas que se hablaban en mi campamento, y con gran asombro descubrí que eran trece. Uno de mis ayudantes y yo éramos franceses; de los dos jóvenes designados por el gobierno boliviano para acompañarme, uno era de Santa Cruz y hablaba español; el segundo, nacido en Cochabamba, tenía como lengua materna el quechua, el idioma de los incas. Un criado que había tomado en La Paz era aymara. Un comerciante brasileño que me acompañaba hablaba portugués. De los tres indiecitos que me habían seguido, uno era chiquito, el otro cuciquia y el tercero, Mbuca ori, era guarayo y hablaba guaraní. Entre mis remeros, dos guardianes de la cabaña eran cayuvavas, y entre ellos se encontraba un pacaguara. $\mathrm{Si}$ a estos idiomas se hubiesen agregado los conocidos por mis intérpretes, su número hubiese sido mucho más considerable. De todas esas lenguas, las más próximas eran sin discusión las europeas, porque entre las demás no había a menudo más nexo que el de las reglas gramaticales, ya que todas las palabras eran diferentes. Nada tan extraordinario como esta diversidad de lenguas que se encuentra en América». (D’Orbigny, 2002a, IV: 1467) (El énfasis nos pertenece.)

Todo parece indicar que la p.resencia de uno de los franceses también fue efectiva en el viaje a Moxos. Sabemos que d'Orbigny

«Por informes que me suministraron algunos comerciantes de Cochabamba conocía las dificultades y peligros a que está expuesto en el trayecto hasta esa ciudad a través de la Cordillera. Por consiguiente, resolví intentar la apertura de una nueva ruta con Moxos por el Río Securi, cuya desembocadura había reconocido. A tal efecto, sabiendo que a mi regreso debía emprender una larga navegación con hombres sin

5 Archivo y Biblioteca Nacionales de Bolivia. Ministerio del Interior, Tomo 34, No 14. «Al Señor Presidente de la República Boliviana de Alcide Dessalines d'Orbigny» (La Paz, 12 de junio de 1830). 
experiencia, conseguí que uno de mis intérpretes — un cayuvava llamado Anselmo, hombre muy conocedor de las cosas locales y buen remero-, conscientes en abandonar a sus compatriotas para venir conmigo hasta Cochabamba; era una hazaña de su parte, puesto que antes que él ningún indio de Moxos había trepado hasta la Cordillera. Me informé también que un cochabambino emprendedor Ilamado Amito, acostumbrado a comerciar con los yuracarés, conocía bastante bien la lengua de esta nación como para servirme de intérprete; lo hice venir, y por él me enteré que la nación yuracaré efectivamente habitaba muy al norte todo el pie de las montañas. Le ofrecí seguirme, y aceptó. Terminados estos preparativos, dividí a mi gente, dejando en ese punto a mis preparadores encargados de completar mis colecciones, y me ocupé de los medios de llegar a Cochabamba». (d'Orbigny, 2002a, IV: 1504)

Aunque en la cita precedente no hay una mención explícita acerca de la nacionalidad de sus preparadores, sírvanos aquí como punto de apoyo para afirmar que uno de ellos era Rossignon, quien desarrolló su actividad de manera casi frenética en el período de trabajo con d'Orbigny, a quien transmitía las informaciones y muestras de la naturaleza para el Muséum. Aunque claro, no se descarta el aprendizaje que pudo tener al lado d'Orbigny, quien fue considerado un científico «aplicado y escrupuloso» a pesar de carecer de la especialización en ornitología, lo cual no fue un impedimento para enviar al Muséum el mayor número de especies que recibió (entre diciembre de 1830 y febrero de 1834) (Cuisin, 2002: 52-53).

Sin embargo, en algunos momentos de su expedición tuvo otros ayudantes europeos, como es el caso del Moritz Bach (1800-1860), quien copió el mapa de Santa Ana de Chiquitos que acababa de elaborar d'Orbigny (Barnadas, 2002: 245-246):

«En el vivac siempre se es madrugador; desde el alba, pues estaba en pie y apuraba a mis arrieros. Mi grupo se componía de un alemán, don Mauricio Bach, que me acompañaba como aficionado; dos jóvenes nombrados por el gobierno boliviano, don Manuel Paz y don Joaquín; un ayudante belga, dos sirvientes —un intérprete de quechua y aymara y el otro viejo habitante de Moxos-y dos muleteros cruceños. Éramos nueve personas en total y teníamos siete mulas de carga. Esta escolta, bien armada de fusiles y lanzas, tenía un aire imponente». (d'Orbigny, 2002a, III:1 257)

Se habrá reconocido, en las citas, la presencia de europeos en calidad de ayudantes científicos que en circunstancias diversas hacen su aparición, dejando de manifestarse después en la narración, consecuentemente perdiendo toda traza documental. De tal manera que futuros trabajos deberán establecer la composición de la expedición de d'Orbigny a lo largo de su trayecto. En todo caso, sigamos las trazas de Rossignon.

\subsection{Un taxidermista francés explora, caza y es administrador del estado boliviano}

La composición de la expedición de d'Orbigny se vuelve más nítida gracias a un manuscrito inédito de naturaleza jurídica, ubicado recientemente en el Fondo de la Prefectura de La Paz; en medio de una variada y numerosa documentación de la serie denominada: Expedientes Prefecturales, sobre asuntos que competen a la jurisdicción de esa institución, la cual también realizaba las operaciones de policía judicial6. ¿Por qué no comenzar pasando revista a las diligencias emprendidas?

6 El ordenamiento de la serie Expediente de la Prefectura de La Paz actualmente se lleva a cabo por docentesarchivistas en el Archivo de La Paz, proceso en el que participé activamente en el 2003. 
Apoyándome en esa documentación, mostraré cómo una Resolución de la Prefectura y Comandancia General del Departamento de La Paz de Ayacucho, del 20 de septiembre de 1847, ordena iniciar las diligencias de la policía judicial en el caso del posible suicidio de Rossignon. La Prefectura estaba obligada a dilucidar el caso y, sobre todo, se veía apremiada por la esperanza de ofrecer una explicación coherente al presidente de la república José Ballivián (1841-1847), quien presionaba para que se actuara de manera rápida. No solo porque era un admirador de la obra científica de d'Orbigny, sino también porque tenía un interés particular como coleccionista de aves del territorio boliviano.

Ilustraré cómo este doble relato de investigación policial y de narración del Prefecto y tres testigos son elementos de búsqueda de datos para que la Prefectura, a través de indicios e inferencias, establezca los móviles del suicidio de Rossignon (cf. cuadro 1). De esta manera, las autoridades debían llenar un vacío de información: ¿cómo? ¿dónde? y ipor qué se produjo tan trágico incidente? La resolución del enigma apunta a dar con el paradero de sus bienes: ¿dónde están sus instrumentos y, principalmente, la impresionante colección de pájaros que el naturalista había constituido a partir de una intensa labor de investigación en, aproximadamente, dieciséis años de residencia en Caupolican? ¿Se trataba de algunas curiosidades apreciadas por los museos europeos de la época? ¿Acaso eran valiosos apuntes y dibujos con observaciones específicas de la avifauna?

\section{Cuadro 1 - Lista de los interrogados durante las pesquisas policiales para establecer el deceso del francés François Rossignon}

\begin{tabular}{|c|c|c|c|}
\hline Lugar & Fecha & Identidad & Cargo \\
\hline La Paz & 20.9.1847 & José María Gonzáles & $\begin{array}{l}\text { Gobernador de } \\
\text { la provincia }\end{array}$ \\
\hline La Paz & 20.9.1847 & Pedro Deheza & $\begin{array}{l}\text { Propietario en } \\
\text { Caupolican }\end{array}$ \\
\hline La Paz & 20.9.1847 & Ladislao Marin & $\begin{array}{l}\text { Comandante General del } \\
\text { departamento del Beni }\end{array}$ \\
\hline
\end{tabular}

Fuente - Elaboración propia en base al Archivo de La Paz /Expedientes de la Prefectura del departamento de La Paz, 1847, Caja 24, documento 30, folio 1.

Además, se tenía noticias de la existencia de «otras preciosidades» de carácter científico que presumiblemente él poseyó cuando moraba en el cantón Tumupaza. ¿A manos de quién fueron a parar esos objetos después del deceso del naturalista? La meta de la Prefectura — siguiendo el procedimiento en vigencia - era apuntar a un posible juicio verbal penal, iniciando las diligencias de policía judicial —siguiendo el Código Penal de 1836- (cf. República de Bolivia, 1836).

Del proceso se conserva únicamente la resolución prefectural ordenando la información instructiva solicitada por el Gobierno a la Prefectura y Comandancia General del departamento de La Paz, según consta por la rúbrica del Prefecto.

Las acciones de policía judicial duran un mes, desde el 20 de septiembre hasta el 11 de octubre de 1847; sin que se haya podido ubicar las diligencias posteriores, a pesar de una

El fondo de la Corte Departamental de Justicia ha sido ordenado por la Licenciada Miriam Quiroga en 1993, de tal suerte que la búsqueda se halla totalmente apoyada en el catálogo que ella confeccionó. Cf. ALP/Correspondencia administrativa: «De la Lic. Miriam Quiroga Gismondi a la Mtra. Ximena Medinaceli. El informe final de actividades en el Archivo de La Paz» (La Paz, 30 de abril de 2001). 
intensa búsqueda entre los juicios de la Corte Superior de Justicia de La Paz ventilados desde 1847 hasta 1859, es decir, realizando un seguimiento a lo largo de los diez años posteriores a la primera diligencia judicial7.

Este conjunto de datos permite plantear, hipotéticamente, que la presentación de la información no sigue el modelo clásico de la resolución del enigma, pues la institución investigadora no resuelve racionalmente el misterio, identificando al poseedor de los importantes objetos científicos buscados. Un tiempo después, la investigación fue interrumpida intempestivamente porque se produjo un cambio de gobierno y se instauró el gobierno de facto del caudillo militar populista, Manuel Isidoro Belzu Humérez (18481855). Es conocida la enemistad entre este último y el anterior presidente, José Ballivián (1841-1847), al extremo de haber suprimido del presupuesto la asignación votada para la edición del libro Descripción Geográfica, Histórica y Estadística de Bolivia dedicada por d'Orbigny a Don José Ballivián, presidente de la República en 1845. Sin embargo, el libro fue publicado en París ese mismo año, en su primer tomo, bajo los auspicios del gobierno boliviano. Datos que permiten evidenciar la dimensión de la enconada rivalidad entre políticos y militares, quienes podían perfectamente prescindir de la información científica sobre el país. Pero, deshagamos el proceso para marcar esas y otras huellas más adelante.

Entre septiembre y octubre de 1847 se cita a los ciudadanos vinculados al caso Rossignon para prestar declaraciones, principalmente a los gobernadores de Caupolican —en esa época no existía subprefecto como hoy en día-, quienes actuaron como policía judicial de la provincia donde residían permanentemente (República de Bolivia, 1845). Las averiguaciones se realizaron en la ciudad de La Paz debido a la cercanía de la provincia Caupolican, aunque ésta pertenecía al Beni —un departamento creado por el presidente José Ballivián en 1842-.

A la luz de esas declaraciones pretendemos establecer los elementos esenciales del cumplimiento de esta resolución (República de Bolivia, 1836). Pero, antes detengámonos en establecer el vínculo directo con la expedición científica de d'Orbigny para posteriormente tender los hilos que nos permitan comprender los móviles para iniciar esta investigación inédita de un hecho aislado ocurrido en los confines del Beni.

\section{DE LA EXPLORACIÓN, PALMO A PALMO, DEL CAUPOLICAN}

Todo comienza en 1828, cuando d'Orbigny invitó a Rossignon a ser un miembro más en la expedición científica a Bolivia8. Recuérdese que Francia ha sido el primer estado europeo que en 1825, año de la declaración de la independencia nacional, acordó en su homenaje enviar una misión científica a Bolivia. Esta tarea fue encomendada por el gobierno francés al Muséum national d'Histoire naturelle de París; su finalidad era entrar en entendimientos científicos y culturales con Bolivia, la última nación en declararse libre en el continente (Albarracín Millán, 2002: 29). Subrayemos, que el contrato del Muséum era con d'Orbigny, quien tuvo la responsabilidad, a lo largo de su expedición, de subcontratar colaboradores cada vez que lo considere oportuno.

Rossignon, en esa época, no imaginó que el viaje y la experiencia en tierras bolivianas cambiaría radicalmente el curso de su existencia; particularmente, su recorrido por Moxos y Chiquitos, más precisamente, cuando penetró al inexplorado departamento del Beni, iniciando la inspección en la provincia de Caupolican - actualmente provincias Franz Tamayo y Abel Iturralde del departamento de La Paz (fig.1).

8 Carecemos, por el momento, de datos que nos permitan precisar las condiciones del acuerdo que permitió integrar a Rossignon en el cuerpo de ayudantes científicos de d'Orbigny. 
Rossignon estuvo motivado por varios factores. Primero porque el propio d'Orbigny había recibido sugerencias del presidente Andrés de Santa Cruz para explorar Moxos y Chiquitos conjuntamente con Caupolican. Trayectos que Rossignon siguió a la cabeza de la expedición movido por el interés que le causaba la naturaleza, pero también por el deseo de cumplir con el trabajo que le había confiado d'Orbigny y el salario que le ofrecía el gobierno del presidente boliviano 9 . El itinerario propuesto no pudo ser efectuado por d'Orbigny porque padecía de una fiebre que lo tuvo delicado por un buen tiempo y sumado a ello, la intensa actividad para preparar su retorno a Francia. De manera que Caupolican no fue visitado por d'Orbigny.

Segundo, Caupolican era una vasta provincia interesante, posiblemente la «menos conocida de toda América», a pesar de tener las montañas revestidas de «la vegetación más prodigiosa del mundo» ubicadas en la vertiente oriental de la Cordillera —la parte noreste del departamento del Beni de ese entonces-. O sea, era la ocasión para explorar la provincia «más curiosa por su aspecto orográfico» y, quizá por ello, síntesis de la biodiversidad boliviana (d'Orbigny, 1845: 5-6, 14).

Rossignon, lentamente penetró a un territorio inmensamente interesante para los científicos debido a su riqueza en avifauna10. Pero allí también estaban los buscadores de oro, pues era un reservorio minero «en una superficie considerable», razón por la cual abundaban lavaderos. Poco a poco fue siguiendo su configuración orográfica, los ríos y las cadenas de montañas que determinan los grandes valles y las pendientes de los valles secundarios (d'Orbigny, 1845: 8-9). Esa gradación vertiginosa del paisaje lo obligó a soportar una enorme variación de temperaturas: desde los fríos más rigurosos en las montañas hasta los calores más insoportables en las llanuras.

En algunos trayectos de su difícil travesía por terrenos accidentados fue descubriendo poblados en medio de empinadas montañas, frondosos valles o espacios donde la vegetación parecía cubrirlo todo, pero donde a pesar de la tupida selva, se habían logrado formar poblados con grande esfuerzo. En efecto, en esos espacios contrapuestos por su vegetación lograron instalarse agrupaciones humanas étnicamente diversas agrupadas en torno a dos jurisdicciones conformadas por cantones. Una era el Partido Grande que federaba a los pueblos de Suches, Pelechuco, Pata, Moxos, Apolobamba, Santa Cruz de Valle Ameno y Aten. Otra jurisdicción llamada Partido Chico, con los pueblos de San José de Chupiamonas, Tumupaza, Ixiamas y Cavinas (fig.1). A nivel administrativo y formal, Apolobamba constituía la capital de la provincia. Sin embargo, los pobladores del interior reconocían a Ixiamas como su capital de facto. A su vez, estos dos grandes partidos estaban sujetos, en lo religioso, a diez parroquias dirigidas por franciscanos.

Uno de los aspectos que debió llamar más la atención al viajero es la composición multiétnica de los pobladores: Quichua, Apolista, Tacana y «salvajes» de otros grupos (d'Orbigny, 1845: 61). Estas informaciones son importantes, porque nos ofrecen un panorama absolutamente distinto del que se obtiene en base a los padrones y registros de la sub-población tributaria (varones sanos entre 18 y 50 años). Estos padrones mencionan

9 Rossignon ganaba treinta pesos mensuales. Archivo y Biblioteca Nacionales de Bolivia. Ministerio del Interior 22, 16,1833 «A su excelencia el Señor Presidente de la Republica Boliviana de Alcide Dessalines d'Orbigny» ( La Paz, 22 de junio de 1833). Lo extraño es que d'Orbigny, a pesar de haber recibido dinero para el pago de los salarios de sus acompañantes, no mencione el momento de evaluar los ofrecimientos del gobierno de Santa Cruz. «Escribí inmediatamente al gobierno, remitiéndole mis cartas de recomendación. En respuesta me ofreció él su protección, y fondos si lo necesitaba, proponiéndome además un oficial del ejército y dos jóvenes para acompañarme. No queriendo abusar de tan generosas ofertas, acepté, con la mayor gratitud, solamente los dos últimos, así como las facilidades de transporte por toda la república [...]». (d'Orbigny, 1845: xi)

10 El territorio mencionado actualmente bordea el Parque Nacional y Área Natural de Manejo integrado Madidi donde se han detectado 1100 especies de aves para el área, cifra que representa el $90 \%$ de la avifauna de Bolivia. 
que la mayoría de la población entre 1817 y 1848 estaba compuesta por individuos de varias etnias que habían llegado a esas tierras, instalándose en calidad de forasteros sin tierras ${ }^{11}$. Esta presencia cambió radicalmente el panorama lingüístico de la provincia, donde en ciertas zonas se hablaba el quechua (Suches, Pelechuco, Pata o Moxo), en otras el «Apolista» (Apolo, Santa Cruz del Valle Ameno) y Tacana (en los pueblos de interior); razón por la cual era necesario utilizar intérpretes, generalmente presentes en cada población, dispuestos a brindar auxilio a quienes hablaban castellano.

A pesar de la distribución diversificada en las jurisdicciones de los partidos, de la diferenciación étnica y lingüística existían elementos comunes que federaban a los pobladores: la pobreza, con su solidaridad y fraternidad consecuentes al compartir una rica biodiversidad. En efecto, la pobreza era una de las características más sobresalientes de sus habitantes:

«[...] poseen lo necesario para alimentarse a saciedad y para vestirse y procurarse algunos placeres, no pudiendo inquietarlos por otra parte el porvenir de sus hijos, en el seno de esa naturaleza tan fértil. Su pobreza relativa es una verdadera riqueza en el actual estado de cosas; pues icómo desear los objetos de que no se tiene la menor idea!». (d'Orbigny, 1845: 61)

Quizá, por esa razón

«[...] todos ellos se consideran como si perteneciesen a una misma familia, viviendo en la más estrecha fraternidad contando pues con los suyos, jamás un indígena pide a los extranjeros la más mínima cosa». (d'Orbigny, 1845: 61)

Esta aguda información acerca de la organización social imperante en Caupolican equiparada al «estado primitivo» es uno de los elementos que más sorprende al viajero embelesado con la biodiversidad de los diferentes poblados.

\section{DEL TUMUPAZA CORREGIMIENTO DE ROSSIGNON Y SUS AVES}

A medida que Rossignon se adentra en la selva de Caupolican, llega a San José de Chupiamonas, quedando pasmado de admiración al contemplar una vegetación hermosa e infinitamente abundante de frutos. Sus bosques con vainilla, resinas, cortezas aromáticas, gomas; la cera y la miel de abeja y multitud de plantas medicinales (d'Orbigny, 1845: 52). Todo parece indicar que Rossignon estuvo fascinado por San José, pero sobre todo por un pueblo distante a doce leguas al noreste llamado Tumupaza (fig. 1).

A primera vista, se trataba de un caserío en una colina ligera, compuesta de pedregales blanquizcos y emplazada en medio de un campo horizontal cubierto de bosques. Allí sobrevolaba una muchedumbre de pájaros cada cual más precioso, prácticamente funcionando como ornamento a la maravillosa vegetación. Rossignon se sintió cautivado por ese estupendo escenario con concentraciones impresionantes de aves:

«A pocos países ha favorecido la naturaleza tanto como a esta provincia en cuanto a la variedad y belleza del plumaje de los pájaros: sus montañas están animadas por millares de ellos, distinguiéndos entre los más notables, los brillantes tunquis, los cefalópteros, los picaflores, los tanagras, los ampelíes, a cual más bello y una infinidad de loros y de guacamayos habladores que anidan tanto en las montañas, como en los llanos. Encuéntranse en éstos los surucúes y multitud inmensa de otras

11 Cf. Archivo de La Paz. Padrones Republicanos. Libro 1, Caupolican, 1817. Padrón general de naturales del partido de Caupolican formado por el agente fiscal Capitán Don Santiago Giani, matrícula actuada de orden superior y su gravamen al Real Erario. La Paz, 30 de septiembre de 1817; Libro 2, Caupolican, 1848. Matrícula general de indígenas contribuyentes, practicada por José María Mallo. 
especies, admirabilísimas por el lucido matiz de sus plumajes. Vecinos a éstos, es decir, en las llanuras, se presentan al cazador como un bocado exquisito los paujos o pavas del monte, los manacaracos o gallinetas montaraces, los huangues o palomas torcazas». (d'Orbigny, 1845: 67-68)

Todo esto, obviamente, trasciende en la decisión de Rossignon de establecer su viviendagabinete en Tumupaza y consagra su interés de naturalista como un destino. Tempranamente se dedica a escuchar, observar y recoger algunos ejemplares de aves para ser disecadas y transportadas a los museos de París y La Paz. Pero el camino todavía era largo, debía recorrer alrededor de 19 leguas al nordeste de Tumupaza, en el seno de una «inmensa Ilanura entrecortada por bosques y pajonales», para llegar hasta Ixiamas, la capital de facto del Partido Chico. Allí convenía adentrarse por los bosques de palmeras y especies del lugar. Desde Ixiamas recorre una «distancia inmensa» hasta Cavinas que es la última misión de la provincia Caupolican. Allí llegó navegando por el río Beni, el cual pasa por el este, muy cerca del poblado, lo mismo que el río Madidi por el norte (d'Orbigny, 1845: 221).

Ese recorrido lo anima a instalarse en las inmediaciones de Tumupaza compartiendo su existencia principalmente con las aves. Aunque cerca del poblado existían algunos asentamientos dispersos de los indígenas Tacana, organizados en tres parcialidades: ayllu Tacana con 192 indígenas originarios, la parcialidad Marcanis con 86 y finalmente Saparunas con 69 originarios 12 .

No sabemos, a ciencia cierta, las características de la relación existente entre Rossignon, los vecinos de los pueblos y, principalmente, los indígenas. Imaginamos que la actividad del naturalista debió provocar localmente modificaciones considerables en la percepción que se hicieron de la actividad de colecta de especimenes de la naturaleza, particularmente en la valoración de la avifauna. Ésta se convirtió en un foco de interés público y local, creando una dinámica con fines de poder y apropiación por parte de los vecinos, como lo veremos más adelante.

En ese andar, en 1844, Rossignon ocupó el cargo de Corregidor de Tumupaza, teniendo a los pobladores bajo su jurisdicción. ¿Cómo consiguió un francés este nombramiento? Todo indica que él buscó seguridad jurídica para residir en esas tierras apenas exploradas y realizar sus actividades de naturalista con el sentimiento de ser socorrido ante cualquier eventualidad. Para apreciar a cabalidad la dimensión del nombramiento y las redes que movilizó para ello, es suficiente tomar en cuenta lo siguiente: el Corregidor era nombrado por los pobladores anualmente (República de Bolivia, 1826: 101) según un reglamento particular, pero en esencia el cargo era desempeñado como concejil. Intervenía también el Prefecto quien, en última instancia, era el proponente y presentador del candidato a Corregidor. A su vez, el Prefecto era un adepto del presidente en ejercicio, pues era nominado por éste, ya que el Prefecto es el representante del mencionado Gobernante (República de Bolivia, 1826: 101). A partir de esos elementos podemos inferir que Rossignon fue nombrado por el propio presidente Ballivián. Se puede suponer que lo hizo por varias razones: primero, porque rendía un homenaje de admiración a d'Orbigny al proteger a quien fue uno de sus auxiliares científicos. Segundo, porque deseaba apoyar a un taxidermista, pues Ballivián se interesaba en tener expertos debido a su actividad coleccionista. Tercero, fueron consideradas las competencias del francés Rossignon, quien podía administrar perfectamente el juzgado actuando como juez de paz.

Una vez asumido el cargo, como un notable lugareño, nuestro personaje sufre una primera metamorfosis: de François Rossignon, naturalista francés pasa a ser Don Francisco Rosiñon

12 Archivo de La Paz. Serie Padrones Republicanos. Libro 2, Caupolican, 1848. Matrícula general de indígenas contribuyentes, practicada por José María Mallo. 
un administrador del Estado boliviano. No sabemos a cabalidad si la castellanización de su nombre y apellido se produjo oficialmente o simplemente por conveniencia de los lugareños. En todo caso, él atiende los juicios de conciliación en demandas verbales sobre injurias leves; claro está, procedimientos orales que en ningún momento eran escritos porque podían ser resueltos in situ, muy rápidamente. Luego, se ocupa de asuntos sobre negocios de interés que no pasan los 50 pesos (República de Bolivia, 1826: 101). Finalmente, en ocasiones ejerce las veces de juez en los juicios de conciliación en la provincia de Caupolican - como se estilaba en las provincias Mojos, Chiquitos y Cordillera (República de Bolivia, 1826: 101)—.

Su vida estaba profundamente arraigada al pueblo de Tumupaza, los espacios surcados por las aves, y la cadencia de su actividad se sometía a la estacionalidad de los movimientos de las aves. En esas condiciones, terminó viviendo como los tacanas en torno a Tumupaza (uno a dos leguas de distancia del otro) en un espacio fértil y productivo donde logró obtener un terreno «disforme» denominado localmente como cacaguetal. Laboriosamente logró sembrar 5000 plantas, entre las cuales posiblemente predominaba el maní. En otros momentos se dedicaba a la pesca de sábalos y de bagres en los ríos. Y, por supuesto, también a cazar animales, construir colecciones, identificar especies. Pero su actividad principal consistía en adentrarse por el bosque donde es más difícil observar a las aves, porque viven en un hábitat alto, complejo y muchas veces oscuro, lo cual lo conducía a escucharlas y reconocerlas por su canto. Esa actividad derivó en la acumulación estática y sistematizada de especies naturales y su búsqueda obsesiva lo llevó a reunir 500 o más pájaros — según versión de algunos vecinos de la provincia Caupolican-. Lo que significa que había logrado igualar el tamaño de la colección que d'Orbigny había mandado a París entre 1831 y 1834, consistente en 520 aves procedentes de Chile, Perú, Patagonia, Argentina y principalmente Bolivia. A partir de estos datos señalados por M. J. Berlioz, se establece que el $40 \%$ de las aves procedían de Bolivia (Beriloz, 1933: 68). Pero lo que debemos resaltar es que mientras Rossignon, en Bolivia, conformaba su propia colección de aves neo-tropicales, en París d'Orbigny trabajaba en colaboración con el ornitólogo barón Lafresnaye en la sistematización de los especímenes recolectados, trabajo que dará lugar a Synopsis Avium (Beriloz, 1933: 69).

\subsection{Una colección de ornitología neo-tropical, fuente de codicia, atentado y misterio}

Si bien Rossignon aprovecha la abundancia de recursos naturales, se ve limitado en materiales para su trabajo de taxidermista, en parte porque los precios de muchos productos son muy altos debido a la lejanía de su vivienda-gabinete. Eso se debe a la ausencia de una dinámica de libre comercio en Caupolican, pues lo poco que se vendía entre los pobladores era su excedente; a pesar de existir un enorme potencial, particularmente en los bosques de San José de Chupiamonas, Tumupaza, Ixiamas y Cavinas donde existían cantidades de excelente cacao que no podía ser comerciado porque los indígenas se resistían a cargar ese producto, pero, sobre todo, porque las iniciativas comerciales eran absolutamente caóticas (d'Orbigny, 1845: 85).

En todo caso, Rossignon se da cuenta que la única manera de proveerse de lo necesario es a través de las propias autoridades de los cantones quienes le temen por sus apoyos políticos y lo recelan por sus colecciones. Ellos tejieron una tela de araña donde el abuso, la explotación y la falta de respeto a los más elementales derechos humanos, por un lado, atrapan en sus redes a los pobladores y, por el otro les impiden procurarse mercancías a 
precios razonables, empujándolos a alimentar, consolidar y perpetuar ese tejido denso de intereses de las autoridades-comerciantes de los pueblos. Rossignon no tiene más remedio que fomentar esa red para estar bien aprovisionado de productos exóticos en los rincones del Beni (papel, vino, telas, tijeras, entre otros). Esto, porque las experiencias propias y las circunstancias no le proporcionan un terreno lo suficientemente estable para tomar una posición inequívoca frente a las autoridades civiles y militares bolivianas.

Durante las averiguaciones, se supo por testimonio jurado del gobernador de la provincia de Caupolican en 1847 — José María González-que, efectivamente, Rossignon necesitaba de materiales y productos específicos, razón por la cual ofreció su «colección hermosa» de 500 o más pájaros en «venta al fiado» al Comandante Militar del Beni, Ladislao Marín, quien se comprometió a pagar el valor acordado «en especies o efectos».

¿Quién era Marín y cómo estableció relaciones con Rossignon? Marín había entrado al Beni comisionado para elaborar un plano topográfico, pero al igual que el resto de las autoridades locales, deseaba aprovechar su cargo para identificar recursos comercialmente explotables. Sobre todo había comprendido que podía aprovechar la avifauna neo-tropical como una veta para insertarse en la red que monopolizaba la compra-venta de colecciones de objetos naturales. Pero también para utilizar las colecciones como objetos simbólicos para ganarse el favor de individuos que tenían algún poder en la administración del Estado. Las informaciones acerca de la célebre colección de Rossignon y el interés que despertaba por su valor científico le permitieron vislumbrar la posibilidad de apropiársela. De esa manera, podía beneficiarse económicamente porque en el país la situación no era muy floreciente.

Según el testimonio de José María Gonzáles, ambos personajes establecieron un contrato de compra-venta por el cual Rossignon (quizá en un momento de euforia) traspasaba la colección de pájaros a Marín. Sin embargo, este personaje después de recibirla no le remitió el pago. Esta sería la causa por la cual Rossignon «cargó demasiado su espíritu en esta falta de compromiso [de Marín]». ¿Qué había sucedido exactamente, según lo sustentó José María Gonzáles? Desde esta perspectiva, la toma de conciencia de haberse separado, irremediablemente, de un trabajo inmenso plasmado en la «hermosa colección de pájaros» hizo que Rossignon se trastorne al extremo de suicidarse, pues sabía que sería imposible recuperar la colección en julio de 1845.

La Prefectura no se dio por satisfecha con semejante versión. Según un testigo, el coronel Pedro Deheza, la venta se concertó pagando por la colección de pájaros un monto aproximado de 400 varas de bayeta blanca del país. La remisión de esa cantidad de tela habría de hacerla el corregidor de Pelechuco — Bonifacio Miranda - por encargo especial de Marín «quien suplicó al expresado corregidor la remitiese»; pero se ignora si tal pago se habría realizado. El Coronel atribuía a la locura la única causa del suicidio, dejando a los investigadores de la Prefectura sin elementos para emitir cualquier juicio al respecto.

El 20 de septiembre de 1847, se remite la averiguación al Ministro de Estado en el despacho de Gobierno y por ese canal oficial sería transmitido el contenido de los testimonios al presidente José Ballivián (1841-1847), quien ese mismo día, instruye la aceleración del proceso. Primero, para que se nombre un fiscal que esclarezca el paradero de la colección de pájaros. Segundo, se ordena tomar declaraciones al comandante Ladislao Marín sobre el caso. Tercero, se eleve un informe definitivo al Ministerio de Estado en el Despacho de Guerra. Es decir, que implícitamente se aceptó la causa del suicidio debida a la locura de Rossignon. Esto significa que una primera parte de la investigación habría sido resuelta o por lo menos acallada, pues no había argumento contra la privación de la razón. ¿Qué es lo que desde las altas esferas del Beni y Santa Cruz de la Sierra se pretendía callar acerca del deceso del naturalista francés? 
Quizá fue la sospecha de que algo se ocultaba la que desencadenó nuevas investigaciones. En efecto, en La Paz, el 21 de septiembre se ordena al Comandante Mayor de Plaza que reciba la declaración de Marín. Cuatro días después, se nombra como Secretario al subteniente Fernando Cárdenas, quien jura al cargo. Ese mismo día, el Comandante General del Departamento hace comparecer al comandante Ladislao Marín a objeto de tomarle el juramento de rigor. Él promete, bajo palabra de honor, decir la verdad a lo largo del interrogatorio, a partir de preguntas previamente preparadas. Gracias a ese cuestionamiento, sabemos que Marín afirmó poseer la colección de aves. En efecto, en cierto momento fue comprada a Rossignon por una cantidad total de 544 pesos y 4 reales, suma pagada en especies como lo muestra el cuadro 2.

\section{Cuadro 2 - Objetos teóricamente remitidos a François Rossignon como pago de su colección de aves neo-tropicales}

\begin{tabular}{lcl}
\hline \multicolumn{1}{c}{ Objeto } & Cantidad & Precio en Tumupaza \\
\hline Bayeta blanca ${ }^{(a)}$ & 800 varas & 4 reales $x$ vara \\
Tocuyo blanco & 100 varas & 4 reales $x$ vara \\
Madapolán ( $\mathrm{b}$ ) & 100 varas & 4 reales $x$ vara \\
Papel & 3 resmas & 12 pesos $x$ resma \\
Tijeras finas & No indicada & 1 peso \\
Vino de Burdeos & 3 botellas & 20 reales $x$ botella \\
Chalona ${ }^{(c)}$ & 2 piezas & 3 pesos cada una \\
\hline
\end{tabular}

Fuente - Archivo de La Paz. Expedientes de la Prefectura del Departamento de La Paz, 1847, Caja 24, documento 30, folio 4 (elaboración propia).

Nota: (a) Tela de lana, poco tupida realizada en telar del país;

(b) Tela de algodón blanca; lisa y resistente, de buena calidad;

(c) Chalona es carne de oveja secada al sol con sal, técnica de conservación que permite mantenerla por largo tiempo.

¿Qué nos enseña la composición de los pagos? En primer lugar, se produjo una serie de inversiones simbólicas, pues Rossignon le ofrece su importante colección científica de aves neo-tropicales a Marín a cambio de la mercancía símbolo de la colonización: telas. Luego, es el comprador quien impone los precios de los productos a la par de aquellos que rigen en Tumupaza. Finalmente, no existe un desembolso directo en la compra éste debía espaciarse en el tiempo y depender de pagos realizados por terceros (cf. Cuadro 2).

Marín asegura que el precio total cancelado a Rossignon era excesivo, por «los pocos pájaros que recibió», sosteniendo que eran simplemente 200 unidades. Es más: según Marín, aceptó el contrato de compra-venta «[...] con la condición de que le había de mandar [Rossignon] objetos de historia natural, según [los] vaya reuniendo». Las entregas suplementarias estaban plenamente justificadas porque, según Marín, el naturalista había tasado su propia colección en un precio no mayor de 100 pesos. Lo que significaría que Marín habría concedido a Rossignon, un total de 444 pesos por encima de lo estipulado. La intencionalidad probatoria de Marín era convencer a los jueces de que había realizado un mal negocio y que, en última instancia, salió perdiendo debido a la astucia del extranjero, quien detentaba un conocimiento ornitológico, adquirido con la experiencia de años de trabajo. 
El Fiscal estaba interesado en saber si existían otros individuos que tenían conocimiento de la transacción de compra-venta. Además, si estaban enterados del pago efectuado a Rossignon. Según Marín, el total de ocho corregidores de todos los cantones que van desde Pelechuco hasta Tumupaza, fueron los encargados de remitir en mano propia los productos acordados y, consecuentemente participaron de la transacción de manera activa. ¿Cómo entender esta afirmación de Marín? Lo que allí está en juego es muy concretamente plantear la co-responsabilidad de las autoridades administrativas locales encargadas de controlar y monopolizar el tráfico comercial en Caupolican. De tal manera que si alguna falla hubo en el aprovisionamiento a Rossignon, no fue culpa suya, sino de la red que no supo responder a tiempo los compromisos contraídos. Marín, al exponer el argumento, primero deseaba, evidentemente, evadir responsabilidades de un posible incumplimiento en las entregas a Rossignon; luego frenar el interrogatorio y finalmente agrandar el proceso, en caso de seguir su curso. De ahí que él insista que la cancelación de las especies se hizo por terceros de la provincia Caupolican, convirtiendo la investigación en un asunto más complejo debido a la multiplicidad de actores intervinientes.

Marín señala claramente cómo actuó la red: en primer lugar, se encontraba el Gobernador de Caupolican - Casimiro Bacarresa- que «suplió» con 200 pesos para comprar las especies (detalladas en el cuadro 2). Gracias a la intermediación de un vecino de Pelechuco - Caseres - se compró la bayeta (800 varas), la cual fue entregada al corregidor Miranda, conjuntamente con las dos chalonas, mientras que el papel era remitido por el corregidor de Ixiamas que, curiosamente, también era un francés llamado Mercier. Además, intervino un ciudadano habilitado en Tumupaza por la prefectura del Beni —Ángel Fajardo—, quien le entregó las especies; por ese trabajo le pagó el prefecto de Apolo 12 pesos.

Todo esto, obviamente, apunta a mostrar la extensa y tupida red de prefectos y corregidores bolivianos y franceses al mando de dependientes entre los pobladores de los cantones. Todos ellos, claro está, implicados en la transferencia de las especies y productos (cuadro 2). Se habrá visto entonces cómo Marín logró vincular fuertemente a los corregidores, quienes actuaron como subordinados, sin ofrecernos pistas para entender la razón por la cual se aliaron para organizar y participar en la compleja trama que supuso la adquisición de la colección de aves.

A pesar de esos datos interesantes y reveladores, debemos detenernos más largamente en la intencionalidad de las palabras de Marín:

«Y que se ha creído engañado [por Rossignon] [...] porque no le mandó especies que quedó en mandarle, cuanto por haber comprado del ciudadano N. Román de Santa Cruz, objetos de historia natural mucho mas baratos y mejores».

La diferenciación establecida entre ambas colecciones no se muestra como hecha al azar y nos parece que Marín tenía algún conocimiento previo sobre los objetos naturales que lo autorizaban a emitir un juicio de valor. Además, comprobamos que Marín tenía tendidos múltiples hilos en las redes locales del departamento del Beni, pero desde esos hilos se entrama el tejido de entrecruce con los traficantes, coleccionistas y comerciantes de objetos naturales de Santa Cruz de la Sierra.

Pero, Marín sabía que evocar los hechos con tal fuerza de persuasión no es suficiente, de ahí su estrategia de apoyarse en el testimonio de un subordinado suyo —el subteniente Lucio Camacho-, «quien caminó con él [Marín] por espacio de un año y seis meses» en el departamento del Beni, ayudándole con el trazado del mapa, pero también estableciendo contactos para conectar con el entramado de las redes locales.

Además - y esto hay que enfatizarlo- esta afirmación es apoyada por dos grupos de testigos. Por un lado, las personas asalariadas que cazaban y disecaban los animales; por el otro, quienes con «esfuerzos arreglaron» la colección de Rossignon, sin ofrecernos 
elementos precisos acerca de las acciones emprendidas. Curiosamente, ambos grupos estaban conformados por autoridades civiles y militares, especie de «especialistas» locales en Santa Cruz de la Sierra y el Beni. Por su condición, en la sociedad se conectan con los grupos de ilustrados y políticos, consumidores ávidos de procurarse animales disecados, minerales, conchas y aves entre otros. Es decir, aquellos que, copiando a los europeos, consideran la colección como signo de civilización y poder.

Son claras y contundentes las palabras de Marín. Él refiere la existencia de un mercado de coleccionistas militares y civiles deseosos de poseer aves de colección, entre ellos el propio presidente José Ballivián. Marín lo deja entrever porque fue él quien obsequió a esta autoridad una colección de pájaros en calidad presente cuando se levantaba el mapa topográfico del Beni — curiosamente ese regalo era una parte de la colección de Rossignon-.

Volviendo un poco atrás, conviene preguntarse: ¿Qué deseaba el presidente Ballivián al instruir el inicio de la investigación prefectural? ¿Acaso descubrir realmente la causa de muerte de Rossignon o más bien apoderarse de la parte restante de la colección de aves preparadas por Rossignon, completando la suya? La averiguación prefectural dejó claro que el propio prefecto del Beni levantó un inventario de lo encontrado en la viviendagabinete de Rossignon, porque con el correr de los años se había convertido en un lugar clave de acopio de información científica. Asimismo recogió el testimonio de los vecinos, el cual le permitió recuperar los implementos e instrumental de trabajo existentes. El prefecto de ese departamento estaba al tanto de lo que podía hallar porque en sus oficinas cursaba correspondencia según la cual Rossignon era un «cazador de preciosidades de interés científico» desde 1833, cuando el propio presidente Andrés de Santa Cruz lo había presentado a las autoridades locales para que le presenten facilidades tanto en el Beni como en Santa Cruz de la Sierra13. El Prefecto, además, presume que hubo un inventario de los bienes del difunto Rossignon realizado por el Juez de Paz del cantón Tumupaza para ser remitido al Juez de Letras de la provincia Caupolican, Dr. Bernardo Polo — según la versión del corregidor de Tumupaza, Eduardo Barnée-

Hay más, sin embargo, los testigos señalan que se produjo una segunda transformación en nuestro personaje: de respetable naturalista se convirtió en El Loco Rosiñon, una vez que se concreta la transacción con Marín. Este punto de vista de los pobladores locales traduce el consenso para desacreditarlo, utilizando el recurso más común entre los bolivianos para caracterizar a los individuos enigmáticos, inclasificables y atípicos: la acusación de locura, entendida como delito. ¿Cómo se manifestó la locura? Las vagas declaraciones de los testigos esbozan un panorama oscuro de lo sucedido, con informaciones incompletas, plagadas de silencios que dan pauta para que el misterio no se agote.

En suma, como lo ilustra el artículo y lo expresa metafóricamente el título con su plurisemanticidad de significados, el francés François Rossignon se quedó en Bolivia prisionero de sus intereses de naturalista y seducido por su experiencia de explorador al lado de su compatriota d'Orbigny.

Rossignon, al profanar la naturaleza para permanecer en el Beni, no promueve otra cosa que la consagración de un cautiverio junto a las aves como única posibilidad de su existencia. Su intensa actividad pudo asegurarla, solventarla y mantenerla gracias a la inteligente combinación de una triple combinación: de naturalista, de coleccionista

13 Archivo y Biblioteca Nacionales de Bolivia, Ministerio del Interior, 22, 66, 1833 «Al Señor Presidente de la República Boliviana de Alcide Dessalines d'Orbigny» (La Paz, 22 de junio de 1833). 
privado y de funcionario eventual de la administración de los presidentes bolivianos Santa Cruz y Ballivián. Esta complementación no es casual. Rossignon comprendió que existía un interés marcado en las autoridades de alto rango del estado boliviano por las colecciones, pero además descubrió que trabajar para ellos le daba mayor seguridad para proclamar un derecho de apropiación y movilización de muestras de la naturaleza. Actividad que genera interés y recelo en la amplia red de funcionarios civiles y militares en el Beni, quienes en 1845 lo animan a efectuar una transacción de compra-venta de su magnífica colección de aves neo-tropicales y solapadamente lo inducen a su muerte.

A la misteriosa decisión de su repentino «suicidio», se añade otro misterio: ese que gira en torno a la desaparición de sus «preciosidades de carácter científico», sus instrumentos de trabajo y particularmente de la colección de aves. Es evidente que entre ambos misterios no hay una sola mera coincidencia, sino que el vínculo es claro. Así, lo comprendieron los jueces, quiénes establecieron que la vida de Rossignon estaba indisolublemente unida a la de sus aves, y que estas eran el meollo del misterio.

La relación de lo acontecido con Rossignon en los dos vertiginosos días de duración del caso para establecer la causa sumaria sobre su deceso, proyecta una intensa, pero breve luz sobre un individuo cuya visibilidad no habría sido posible, sino hubiera cruzado la penalidad recogida en las fuentes jurídicas. En efecto, en un solo día se acelera todo el procedimiento, llamando a declarar a Marín, el comprador de la colección. Podemos suponer que una de las razones para actuar con tanta rapidez en el procedimiento fue que Marín estaba en servicio activo y lo mandan a declarar rápidamente a La Paz a fin de que regrese inmediatamente después a su puesto militar como comandante en el Beni. No se olvide que desde octubre de 1847, se verifican movimientos de tropas militares en ese departamento con objeto de desestabilizar al presidente Ballivián.

Marín minimiza el valor de la colección de pájaros de Rossignon, pero esa estrategia está destinada a salir del proceso mostrando que fue vilmente engañado por el francés. Sin embargo, es difícil admitirlo porque Marín, desde su condición de comandante militar del Beni, tuvo la astucia de tender los hilos que lo conecten con la red de tráfico comercial en la zona de contacto. Por el momento, desconocemos desde cuándo esta red trabaja en la compra-venta de especímenes de historia natural, pero podemos sospechar que fue Rossignon quien la dinamiza desde el momento que llega a los pueblos de Caupolican con cartas de recomendación del presidente Santa Cruz para que lo apoyen en su empresa.

La presencia del explorador y naturalista genera en los pobladores locales un interés por las colecciones y la conciencia que su posesión no solo significa tener un capital invertido, sino también un bien simbólico que permite acceder a favores políticos (cargos, prebendas y privilegios). Tal es así, que la red de influencias que controlaba la zona de contacto fue capaz de encubrir el posible asesinato de Rossignon. Proceso que fue silenciado por los vertiginosos cambios políticos en el gobierno de Bolivia, cuyos posteriores dirigentes no estuvieron interesados en indagar, una vez más, sobre el destino del llamado Loco Rosiñon.

El proceso de investigación policial de la Prefectura sobre el deceso de Rossignon, nos ha permitido leer lo que d'Orbigny no publicó, lo que no quiso que leyéramos: la existencia de otros colegas franceses coadyuvando a la expedición. Vale la pena resaltarlo: Rossignon fue preparador de las colecciones de ornitología neo-tropical para el flamante Museo de Historia Natural de La Paz y de aquellos ejemplares enviados al Muséum en París.

En parte, ese trabajo lo hizo porque recorrió, palmo a palmo, el departamento del Beni y los recovecos de Caupolican, de manera que se forma una imagen de sus riquezas naturales y potencialidades económicas. La exploración en la zona de contacto fue llevada a cabo en alrededor de dieciséis años, lo cual conduce a pensar que fue él quien le proporcionó 
información a d'Orbigny sobre el Beni, la cual utilizó en su narración como datos vivenciales sin mencionar a su colega francés. O sea, que en la Descripción geográfica, histórica y estadística de Bolivia (1845) existe un juego sobre la ambigüedad de quien transcribe la información. D'Orbigny nunca estuvo en Caupolican, pero su narrativa está destinada a mostrar lo contrario, aunque lo delata el mapa que acompaña a su obra Voyage dans l'Amérique Méridionale donde no hay camino trazado que lo haya conducido a esa zona. Subrayo que la ambigüedad en la transcripción del relato no es nueva, baste recordar que d'Orbigny tampoco realizó el viaje por las pampas de la Cruz Guerra en la Argentina y fue también un francés, su «culto amigo Parchappe que ha recorrido esas regiones australes [...] ha querido transmitirme todos los materiales». Gracias a este gesto voluntarioso de su compatriota, d'Orbigny se apropia en su discurso de las informaciones, de las viviencias y las hace claramente suyas, al extremo de darles una secuencia cronológica ficticia (cf. d'Orbigny, 2002a, II: 539; Kircheimer, 1995).

Los documentos analizados — como diría Paul Ricoeur- nos dejan la sensación que en Voyage dans l'Amérique Méridionale hay mucha memoria al narrar ciertos eventos y descripciones, al mismo tiempo, mucho de olvido en otros pasajes. Enfatizo que los silencios se encuentran sobre todo en la actuación de los informantes, ayudantes científicos y pobladores locales, cuya intervención fue oportuna, clave y significativa para la consecución de la exploración. Lo que significa que los futuros análisis tendrán que prestar más atención a la copresencia e interacción con los ayudantes científicos. No menos significativo es evidenciar la articulación narrativa entre los planos de la propia experiencia de viaje con los de realidad que se vuelven ficción, los de la ficción que se vuelven realidad y se convierten en narrativa de viaje.

\section{Referencias citadas}

\section{Fuentes de Archivo}

Archivo y Biblioteca Nacionales de Bolivia, Sucre (ANB)

ANB/MI. Ministerio del Interior Tomo 28, № 12 «Al Señor Ministro de Relaciones Exteriores en Chuquisaca de Alcide Dessalines d'Orbigny» (La Paz, 4 de julio de 1830), 2 fs.

ANB/MI. Ministerio del Interior. «A su gracia el Ministro del Interior de Alcide Dessalines d'Orbigny» (Chuquisaca, febrero de 1833) $1 \mathrm{f}$.

ANB/MI. Ministerio del Interior Tomo 34, № 14 «Al Señor Presidente de la Republica Boliviana de Alcide Dessalines d'Orbigny» ( La Paz, 12 de junio de 1830).

ANB/MI. Ministerio del Interior Tomo 22, № 6 «A su Excelencia el Señor Presidente de la República Boliviana de Alcide d'Orbigny» (La Paz, 22 de junio de 1833), 2 f.

Archivo de La Paz, Universidad Mayor de San Andrés (ALP)

ALP/EP. Expedientes de la Prefectura del departamento de La Paz, 1847, Caja 24, documento 30, 5 fs.

ALP/PR. Padrones Republicanos. 1817. Libro 1, Caupolican, Padrón general de naturales del partido de Caupolican formado por el agente fiscal Capitán Don Santiago Giani, matrícula actuada de orden superior y su gravamen al Real Erario. La Paz, 30 de septiembre de 1817. 
ALP/PR. 1848. Libro 2, Caupolican. Matrícula general de indígenas contribuyentes, practicada por José María Mallo.

ALP/Correspondencia administrativa. «De la Lic. Miriam Quiroga Gismondi a la Mtra. Ximena Medinaceli. El informe final de actividades en el Archivo de La Paz» (La Paz, 30 de junio de 2001).

ALBARRACíN MILLÁN, J., 1976 - Orígenes del Pensamiento social contemporáneo boliviano. Sociología boliviana contemporánea. T. I, 218 p.; La Paz: Empresa Editora Universo.

ALBARRACÍN MILLÁN, J., 2002 - Una visión esplendorosa de Bolivia. Las exploraciones de Alcides d'Orbigny en Bolivia, 426 p.; La Paz: Plural Editores.

ARZE AGUIRRE, R., 2002 - El naturalista francés Alcide d'Orbigny en la visión de los bolivianos, 402 p; La Paz: Embajada de Francia en Bolivia, IFEA, Plural Editores.

BARNADAS, J. M., 2002 - Bach, Moritz. In: Diccionario Histórico de Bolivia (Barnadas, J. M., dir., Calvo, G. \& Ticlla, J.), 1: 245-246; Sucre: Grupo de Estudios Históricos.

BÉRAUD, G., 2002 - Le départ d'Alcide d'Orbigny pour l'Amérique Méridionale et sa préparation. In: Annales de la Société des Sciences Naturelles de la CharenteMaritime. Muséum d'Histoire naturelle, VIII (9): 1117-1129; La Rochelle.

BERLIOZ, M. J., 1833 - D'Orbigny ornithologiste. In: Commémoration du Voyage d'Alcide d'Orbigny: 66-74; Publications du Muséum national d'histoire naturelle, 3 (MassonTours).

CÁRDENAS, M., 2002 - El naturalista Alcide Dessalines d'Orbigny. In: El naturalista francés Alcide d'Orbigny en la visión de los bolivianos (Arze Agruirre, R., comp.): 163-171; La Paz: Embajada de Francia en Bolivia - IFEA - Plural Editores.

CUISIN, J., 2002 - D'Orbigny, ou le voyage d'un ornithologiste. In: Alcide d'Orbigny. Du nouveau monde... au passé du monde (Taquet, P., dir.): 51-55; París: Nathan Muséum national d'Histoire naturelle.

DÍAZ ARGUEDAS, J., 2002 - Alcide d'Orbigny: estudios sobre la geología de Bolivia. In: El naturalista francés Alcide d'Orbigny en la visión de los bolivianos (Arze Aguirre, R., Comp.): 195-209; La Paz: Embajada de Francia en Bolivia, IFEA, Plural Editores.

DICTIONNAIRE UNIVERSEL D'HISTOIRE NATURELLE, 1849 - Antique Prints from D'orbigny. Se puede encontrar en http://www.panteek.com/DOrbignyF/df_index. htm/

D'ORBIGNY, A., 1845 - Descripción geográfica, histórica y estadística de Bolivia dedicada a su excelencia el General Don José Ballivián (Tomo Primero), 402 p.; París: Librería de los Señores Gide y Compañía.

D'ORBIGNY, A., 1847 - Voyage dans l'Amérique Méridionale (Le Brésil, La République Orientale de I'Uruguay, La République Argentine, La République du Chili, La République de Bolivie, La République du Pérou), éxécuté pendant les années 1826, 1827, 1828, 1829, 1830, 1831, 1832 et 1833 (7 vols); París: Chez. P. Bertrand.

D'ORBIGNY, A., 2002a - Viaje a la América Meridional. Brasil - República del Uruguay - República Argentina-La Patagonia - República de Chile - República de Bolivia - República del Perú (4 vols); La Paz- Bolivia: Instituto Francés de Estudios Andinos - Plural editores (Travaux de l'Institut Français d'Études Andines, Tomo 154).

D'ORBIGNY, A., 2002b - Lettres d'Amérique, 132 p.; La Rochelle: Rumeur des Âges. Éditées par Gilles Béraud avec la collaboration de Enric Miret \& Daniel Dory.

KIRCHEIMER, J. G., 1995 - Narcisse Parchappe : un polytechnicien explore la Patagonie, 
1838. In: Les Naturalistes français en Amérique du Sud XVI-XIXe siècles (Laissus, Y., ed.): 307-315; París: ed. CTHS.

MENDOZA, G., 2002a - D'Orbigny en Bolivia. In: El naturalista francés Alcide d'Orbigny en la visión de los bolivianos (Arze Aguirre R., comp.): 211-234; La Paz: Embajada de Francia en Bolivia - IFEA - Plural Editores.

MENDOZA, G., 2002b - La influencia de Alcide D'Orbigny sobre Melchor María Mercado en la creación artística y en su obra de naturalista, museólogo, explorador. In: El naturalista francés Alcide d'Orbigny en la visión de los bolivianos (Arze Aguirre R. Comp.): 235-258; La Paz: Embajada de Francia en Bolivia - IFEA - Plural Editores.

MORENO, G. R., 2002 - La obra del célebre naturalista Alcide d'Orbigny en los ensayos críticos de la Biblioteca Boliviana. In: El naturalista francés Alcide d'Orbigny en la visión de los bolivianos (Arze Aguirre, R., comp.): 41-54; La Paz: Embajada de Francia en Bolivia - IFEA - Plural Editores.

MUÑOZ REYES, J., 2002 - El insigne científico francés Alcide d'Orbigny en Bolivia. In: El naturalista francés Alcide d'Orbigny en la visión de los bolivianos (Arze Aguirre R., comp.): 259-266; La Paz: Embajada de Francia en Bolivia - IFEA - Plural Editores.

PAREJAS MORENO, A., 2002 - Alcide d'Orbigny: viaje por tierras cruceñas. In: El naturalista francés Alcide d'Orbigny en la visión de los bolivianos (Arze Aguirre, R., comp.): 295-305; La Paz: Embajada de Francia en Bolivia - IFEA - Plural Editores.

PAREJAS MORENO, A. \& MUÑOZ REYES DE PAREJAS, C., 2002 - Noticias sobre arqueología boliviana en la obra de d'Orbigny. In: El naturalista francés Alcide d'Orbigny en la visión de los bolivianos (Arze Aguirre, R., comp.): 267-294; La Paz: Embajada de Francia en Bolivia - IFEA - Plural Editores.

PRATT, M. L., 1997 [1992] - Ojos Imperiales. Literatura de viajes y transculturación, 385 p.; Buenos Aires: Universidad Nacional de Quilmes. Traducido por Ofelia Castillo.

REPÚBLICA DE BOLIVIA, 1826 - Colección Oficial de Leyes, Decretos, Ordenes de la República Boliviana Años de 1825 y 1826, 333 p.; La Paz: Imprenta Artística. 2a edición.

REPÚBLICA DE BOLIVIA, 1836 - Código Penal Santa Cruz, 219 p.; Chuquisaca: Imprenta Boliviana.

REPÚBLICA DE BOLIVIA, 1845 - Colección Oficial de Leyes, Decretos, Ordenes y Resoluciones Supremas de la República, 352 p.; Sucre: Imprenta Boliviana.

RICCEUR, P., 2000 - La mémoire, I'histoire, l'oubli, 400 p.; París: Seuil (L'ordre philosophique).

TAQUET, P., 2002 - Alcide d'Orbigny. Du nouveau monde... au passé du monde, 127 p., Paris: Nathan - Muséum national d'Histoire naturelle. Textes rassemblés et publiés sous la direction de Philippe Taquet. 